\begin{tabular}{|c|c|c|}
\hline $\begin{array}{l}\text { PKS } \\
\text { PULLIC } \\
\text { KNDOWLEDGE } \\
\text { PROJECT }\end{array}$ & $\begin{array}{c}\text { REVISTA DE GEOGRAFIA } \\
\text { (RECIFE) } \\
\text { http://www.revista.ufpe.br/revistageografia }\end{array}$ & $\begin{array}{l}\text { OJS } \\
\text { OPEN } \\
\text { OPUNAAL } \\
\text { SYSTEMS }\end{array}$ \\
\hline
\end{tabular}

\title{
COMPLEXOS AGROINDUSTRIAIS E REESTRUTURAÇÃO PRODUTIVA DA AGROPECUÁRIA: UMA LEITURA A PARTIR DO DESENVOLVIMENTO DA RELAÇÃO DO VALOR
}

\author{
Carlos Roberto da Silva Maia ${ }^{1}$, Francisco Amaro Gomes de Alencar ${ }^{2}$, Israel \\ Rodrigues Bezerra ${ }^{3}$
}

\begin{abstract}
${ }^{1}$ Doutor em Geografia pela Universidade Federal do Ceará, Professor Titular do Centro Universitário Sete de Setembro. E-mail: robertoeco84@gmail.com

${ }^{2}$ Professor Adjunto do Departamento de Geografia da Universidade Federal do Ceará. Email: famaro.ufc@gmail.com

33estrando em Geografia pela Universidade Federal do Ceará.Email: israelbezerra.1995@gmail.com
\end{abstract}

Artigo recebido em 08/08/2017 e aceito em 25/03/2018

\begin{abstract}
RESUMO
O texto estabelece um marco analítico acerca da questão agrária, a partir da leitura da contradição central do desenvolvimento do capital enunciada por Marx, demonstrando o sentido das transformações capitalistas dos processos de trabalho agrícola. Nesse sentido, a questão agrária no Brasil é problematizada a partir da formação dos Complexos Agroindustriais como estruturas capitalistas representantes do aprofundamento da relação do valor e da produção baseada no valor também na agricultura e do seu desdobramento sobre a agricultura camponesa. Por fỉm, indaga-se sobre o papel, ainda não consolidado, a ser desempenhado pelo campesinato no âmbito da transformação substantiva da sociedade, sobretudo num momento em que a questão agrária mais do que nunca, passa a integrar o contexto da mundialização do capital.
\end{abstract}

Palavras-chave: Valor; Capital; Questão Agrária; Campesinato.

\section{AGROINDUSTRIAL COMPLEXES AND PRODUCTIVE RESTRUCTURING OF AGRICULTURE: A READING FROM THE DEVELOPMENT OF THE VALUE RELATIONSHIP}

\begin{abstract}
The text establishes an analytical framework on the agrarian question, starting from the central contradiction of the development of the capital enunciated by Marx, demonstrating the meaning of the capitalist transformations of the processes of agricultural work. In this sense, the agrarian question in Brazil is problematized from the formation of the Agroindustrial Complexes as capitalist structures representing the deepening of the relation of value and production based on value also in agriculture and its unfolding on peasant agriculture. Finally, the question is asked about the role of the peasantry in the context of the substantive transformation of society, which has not yet been consolidated, especially at a time when the agrarian question is more than ever integrated into the context of the globalization of capital.
\end{abstract}

Palavras-chave: Value; Capital; Agrarian Question; Peasantry. 


\section{INTRODUÇÃO}

A questão agrária é um conjunto complexo de aspectos sociais, econômicos, políticos, geográficos, culturais e ecológicos, relativos ao condicionamento da produção do espaço agrário e das atividades agropecuárias por um modo de produção determinado social e historicamente. Da perspectiva do paradigma da questão agrária, aqui assumido como referência, sob o sistema capitalista essa questão não é solucionável, visto que ela é produzida e reproduzida por sua própria lógica sistêmica, manifestando-se de forma diferenciada no espaço e no tempo, conforme o estágio de desenvolvimento e o direcionamento das forças produtivas e das relações de produção capitalistas no campo.

Enquanto aspecto estrutural das formações econômico-sociais (MARX, 1986; MARX, 2011), a questão agrária não se constitui num problema próprio da formação econômico-social capitalista, mas também das que o precederam (sociedades escravistas e feudais), bem como de economias que se propõem a superá-lo, como é o caso dos países de economia planificada (FERNANDES, 2013).

Estruturalmente, o que difere é a maneira com que ela se manifesta, através dos seus múltiplos aspectos em cada contexto histórico-social e como afeta de formas e graus distintos (subalternizando, destruindo, diferenciando e/ou proletarizando) a organização do campesinato. No capitalismo, ela se traduz em problemáticas, antigas e novas, tais como: concentração de terra, riqueza, poder, insegurança alimentar, estrangeirização e uso da terra, conformação de Complexos Agroindustriais (CAIs), financeirização da agricultura, commoditização da natureza, territorialização do agronegócio, desterritorialização do campesinato e disputa por políticas públicas, todas essas sintetizadas num movimento dialético, que ora é promotor da destruição do campesinato, ora da sua recriação (OLIVEIRA, 1997; OLIVEIRA, 2010; KHALILI, 20009; FERNANDES, 2015; FERNANDES 2013; CLEMENTS; FERNANDES, 2013; SILVA, 1996).

Como tudo o mais sob o sistema capitalista, na raiz da questão agrária também está a produção baseada no valor e o limite a essa produção, dado pelo próprio processo contraditório de autovalorização do capital, que se expressa sob as mais diversas formas, como: o domínio do valor sobre o valor de uso, do trabalho abstrato sobre o trabalho concreto, do processo de produzir e extrair mais-valia sobre o processo de trabalho, do capital sobre o trabalho e a natureza, do trabalho morto sobre o trabalho vivo (MARX, 2011; MARX, 2012). 
O sistema capitalista reestrutura continuamente todos os setores da economia, tendo como ponto de partida e meta a valorização do capital. Assim, na agricultura, transformações nos processos de trabalho têm sido empreendidas com o fito de integrá-la aos circuitos do capital (produtivo, comercial e financeiro) de modo a ampliar as possibilidades de autovalorização do capital também nessa atividade, que antes desempenhava muito mais e de forma não integrada, a função de produção de gêneros para manutenção da força de trabalho e de sustentação primária da atividade industrial e urbana de um modo geral.

A reestruturação produtiva da agricultura chega ao espaço agrário, mediante a flexibilização dos territórios nacionais e progressiva difusão dos sistemas de técnicas e objetos típicos do período técnico-científico-informacional do sistema capitalista (SANTOS, 2000). Isso resulta na emergência do que se passou recentemente a denominar por agricultura científica (FREDERICO, 2011), mas que se inicia com a passagem da fase dos complexos agroexportadores para a dos Complexos Agroindustriais (CAIs) (SILVA, 1996) e toda a modernização característica da hegemonização da economia do agronegócio.

A adequação e flexibilidade territorial do meio agrário passam então a ser necessárias e exigidas pela seletividade espacial dos investimentos típicos da economia globalizada, que em busca de regiões especializadas produtivamente (TOLEDO, 2007) e que proporcionem novas oportunidades de negócio, não poderia se dar com o sistema de técnicas da agricultura anterior aos CAIs, pois o mesmo não se compatibilizava mais com a racionalidade financeira da economia-mundo (ELIAS, 2005).

Em termos de uma leitura agrária, isso implica numa reestruturação das relações de trabalho no campo, que se desdobra em processos de diferenciação (KAUTSKY, 1980), desintegração (LÊNIN, 1982) e de reprodução-recriação do campesinato (MARQUES, 2008; FERNANDES, 2013; GUZMÁN; MOLINA, 2013) como expressão da resistência do trabalho vivo no âmbito dos processos produtivos agrícolas. Se na agricultura, assim como na indústria e devido à integração com esta, a criação de riqueza passa a depender cada vez menos do tempo e da quantidade de trabalho vivo do camponês e cada vez mais do poder dos agentes científicos e mecânicos possibilitados pela engenharia agrônoma e genética (MOREIRA, 2007), faz-se pertinente discutir, a partir da formação dos CAIs como estes circunscrevem-se ao processo de financeirização da agricultura e de hegemonização da economia do agronegócio (DELGADO, 2012) e como eles concorrerem para o aprofundamento da subordinação do trabalho vivo no campo. 
Para tanto, o presente artigo realiza uma exploração teórica acerca desse tema, fundamentada em dois aspectos: 1) na teoria do valor e na evolução da produção baseada no valor (MARX, 2012); e 2) nos princípios do paradigma da questão agrária (PQA), assumido como referência analítica para se compreender a condição camponesa no contexto da integração da sua força de trabalho (PAULILO, 1990; SILVA, 2009; FERNANDES, 2015) aos CAIs e ao processo de reestruturação produtiva a eles relacionado.

Inicialmente, será estabelecido um marco analítico sobre o desenvolvimento da relação do valor e a substituição do trabalho vivo pelo trabalho morto, relacionando-a aos CAIs e à emergência da agricultura científica. Em seguida, será tecida uma discussão sobre a condição do trabalho camponês em meio ao processo deflagrado de integração agroindustrial, que é condicionado pela financeirização da agropecuária e hegemonia da economia do agronegócio.

\section{DESENVOLVIMENTO DA RELAÇÃO DO VALOR E A AGRICULTURA CIENTÍFICA}

A questão agrária mantém, em suas mais variadas formas de expressão, um nexo estrutural com as transformações dos processos de trabalho e das relações de produção capitalista no campo. Ela manifesta-se, portanto, em profundidade e amplitude de maneira diferenciada no tempo e no- espaço em função do estágio de difusão e desenvolvimento técnico-científico-informacional (SANTOS, 2000) posto a serviço da acumulação de capital sobre o espaço agrário de cada país.

Situar a questão agrária no âmbito da dinâmica contraditória do capitalismo, significa estabelecer uma relação estrutural entre a sua dinâmica econômico-social (MARX, 2011) e a produção do espaço agrário, permitindo compreendê-la à luz das mediações entre a economia e a geografia agrária. Em síntese, ela significa - admitida de um ponto de vista dialético - um aspecto integrante da totalidade concreta que é a economia-mundo capitalista, cuja lógica da globalização financeira impera e condiciona as dinâmicas espaciais nas mais diversas escalas.

Totalidade concreta da qual não se pretende conhecer todos os aspectos da sua realidade, mas compreender que há uma infinidade de aspectos e propriedades que compõem o seu quadro "total" da realidade e que são produzidos pelo mesmo, sobre o qual se pode lançar uma teoria da realidade e do conhecimento que dele se tem como realidade (KOSIK, 2002). 
Enquanto aspecto estrutural do capitalismo, as condicionantes e resultantes, que integram o quadro da questão agrária, traduzem as determinações da totalidade que é o sistema-mundo capitalista (WALLERSTEIN, 1989). Suas expressões (a propriedade privada da terra; concentração fundiária; expropriação e expulsão dos trabalhadores rurais: camponeses e assalariados; reforma agrária; soberania e insegurança alimentar; estrangeirização e mercado de terras, disputa por modelos e políticas públicas de desenvolvimento agrícola e agrário, padrões tecnológicos, dentre outras) se manifestam diferenciadamente de país para país, em função de fatores (políticos, financeiros, técnicocientíficos, produtivos etc.) globais do capital sobre a estrutura produtiva da agricultura (FERNANDES, 2000, DELGADO, 2012).

Agora integrada à mundialização do capital, embora esteja sempre sob certas regulações locais e nacionais, a agropecuária referencia-se cada vez mais planetariamente, sofrendo as influências das mesmas leis, que regem os outros aspectos e escalas da reprodução econômica e espacial do capital (SANTOS, 2000). Pode-se dizer que a questão agrária no capitalismo deixa de ser um problema, cujas causas residem apenas em dinâmicas nacionais, mas também globais, referenciadas agora nos interesses globais de investidores financeiros.

A rentabilidade do capital, imposta globalmente agora sob o padrão de acumulação de dominância financeira, induz e impõe a existência de formas mais eficazes de produção, o que por sua fez motiva uma transformação técnico-científico-informacional das forças produtivas da agropecuária, sobrepujando os sistemas técnicos anteriores e não condizentes com a racionalidade financeira da acumulação de capital (ELIAS, 2005).

É próprio do período técnico-cientifico-informacional característico da globalização financeira do capital extrapolar a escala local e o domínio das nações sobre os seus recursos territoriais, bem como determinar o sentido do desenvolvimento e da aplicação das forças produtivas, o que vai implicar em termos da questão agrária, tanto na organização produtiva da agricultura, como na destinação das terras agricultáveis.

A agricultura brasileira, por exemplo, passa a expressar esse caráter globalizado ao longo da segunda metade do século XX, quando sofre transformações em sua base técnica, na sua relação com outros ramos da indústria e na sua espacialização, quando à sua organização produtiva tradicional de base local e determinada regionalmente, se sobrepõe uma agricultura científica (FREDERICO, 2011), na qual a "tecnologia e o capital passam a 
subordinar, em parte, a própria natureza, reproduzindo artificialmente algumas das condições necessárias à produção agropecuária" (ELIAS, 2005, p. 4477).

A subsunção da ciência e da tecnologia ao processo de produção do capital é levada ao limite, tornando a agricultura cada vez mais dependente dos insumos da indústria agroquímica e de máquinas, cuja produção transformou o conjunto de meios de produção agrícola. A esse processo está relacionada a passagem da subsunção formal (separação dos trabalhadores dos seus meios de produção e quando os mesmos ainda detêm, em parte, conhecimentos e controle sobre a execução dos processos produtivos) à subsunção real do trabalho camponês ao capital (quando além de expropriados, os trabalhadores se tornam parte redundante e perfeitamente substituível dos processos produtivos) (MARX, 1978).

O controle técnico-científico-informacional do processo produtivo na agricultura, é progressivamente transferido para os meios de produção, com o objetivo de potencializar a extração de mais-valia relativa. Isso fica mais evidente com a modernização conservadora iniciada entre os anos de 1950 e 1960, quando se inicia a transformação da base técnica de produção rural e a constituição dos denominados complexos agroindustriais (DELGADO, 2012).

No Brasil, com a passagem do complexo rural agroexportador aos complexos agroindustriais, consumada entre as décadas de 1930 e 1980, se intensifica a divisão do trabalho e as trocas intersetoriais, a especialização da produção agrícola e substituição das exportações pelo consumo produtivo interno, como elemento central da alocação dos recursos produtivos no setor agropecuário (SILVA, 1996).

Os Complexos Agroindustriais (CAIs), representam um marco na transformação da agricultura pela indústria, que apenas sob o padrão técnico-científico-informacional e de acumulação financeira de capital (CHESNAIS, 1996), foi capaz de abarcar toda a organização da produção agrícola. Com eles, modifica-se a feição da agricultura tradicional, mediante o aprofundamento do processo de integração (técnica e de capitais) que caracteriza a fase cientifica da agricultura e da economia do agronegócio (DELGADO, 2012).

A modernização da agricultura, [...] consiste num processo genérico de crescente integração da agricultura no sistema capitalista industrial, especialmente por meio de mudanças tecnológicas e de ruptura das relações de produção arcaicas e do domínio do capital comercial, processo que perpassa várias décadas e se acentua após a década de 60. Na conformação do atual padrão de desenvolvimento agrícola o processo de modernização passou por três momentos decisivos: o da constituição 
dos CAIs, o da industrialização da agricultura e o mais recente, da integração de capitais intersetoriais sob o comando do capital financeiro (SILVA, 1996, p. 30-31).

No mesmo sentido, Frederico (2011) subdivide a modernização agrícola brasileira em dois momentos: 1) a adoção do paradigma da Revolução Verde, pela constituição dos CAIs e pela centralidade da atuação do Estado; e 2) a emergência de sistemas técnicos informacionais e pela “desregulamentação" política e econômica. Com os CAIs foi possível se induzir maior eficiência e ampliar a escala de produção da agricultura capitalista. Isso ocorre fundamentalmente após a década de 1960, quando a integração da agricultura à indústria se intensifica, permitindo a essa última comandar "a direção, as formas e o ritmo da mudança na base técnica agrícola" (SILVA, 1996, p.32).

A reestruturação produtiva da agricultura aí iniciada revela a tendência à elevação da composição orgânica do capital - predominância do trabalho objetivado (capital fixo) em relação ao trabalho vivo (capital variável) - motivada pela impossibilidade, até então, de controle total do processo produtivo da agricultura e da pecuária. Devido a uma estrutura produtiva demasiadamente dependente dos fatores humanos e naturais mais diversos, o que sempre representou um limite para a acumulação de capital no setor, o controle só foi possível com a superação progressiva da incompatibilidade entre o tempo de produção da natureza o tempo de trabalho (ELIAS, 2005).

Historicamente, o capital vai elevando sua composição orgânica, ou seja, incorporam-se novas tecnologias à produção, ampliando a participação do capital fixo em detrimento do capital variável. Contraditoriamente, ao tornar assim mais eficiente a sua produção, reduz a participação dos produtores diretos nos processos produtivos. A otimização da produtividade do trabalho leva cada unidade produzida a comportar um quantum menor de tempo de trabalho (OLIVEIRA; MOREIRA; MARQUES, 2007).

A diminuição do quantum de trabalho vivo é uma tendência percebida por Silva (1996) no processo de agroindustrialização, o que é corroborado pelo salto do consumo intermediário (consumo de bens de capital e insumos agroquímicos) na agricultura brasileira de menos de $15 \%$ em 1949 para quase $40 \%$ em 1980. Observa-se com esse crescimento do consumo, a integração da agricultura a outros setores da economia, intensificada a partir de 1960.

A agricultura científica faz da produção de riqueza material uma resultante cada vez menos dependente do tempo de trabalho empregado diretamente, se considerado o 
conteúdo científico e tecnológico agregado a ela (MARX, 2012). Nesse sentido tem se orientado todo processo de reestruturação produtiva da agricultura de maneira a conformar o que no século XXI, somado à financeirização do setor, se denomina como a economia do agronegócio (DELGADO, 2012).

Em sua teoria do valor, Marx afirma que é a partir do desenvolvimento lógico do valor como forma mais geral, abstrata e elementar que se pode compreender a natureza da reprodução do capital e suas contradições. Assim como na indústria, os processos produtivos agropecuários e todas as transformações materiais que os envolvem, terão como finalidade a expansão do valor, convertendo-se tudo em capital, ou seja, valor que se autovaloriza (MARX, 2011). Isso é corroborado da seguinte forma nas palavras de Elias (2005, p. 447)

\begin{abstract}
A aplicação dos procedimentos e métodos científicos para a realização da agropecuária, visando ao aumento de produtividade e à redução de custos, aperfeiçoou e expandiu seu processo produtivo, induzindo importantes progressos técnicos que foram determinantes para imprimir complexas inovações às forças produtivas do setor. Com a pesquisa tecnológica foi possível reestruturar a base técnica empregada nesse conjunto de atividades, transformando os tradicionais sistemas técnicos agrícolas e abrindo um grande número de novas possibilidades para a realização da mais-valia mundializada, através da fusão de capitais com os demais setores econômicos.
\end{abstract}

As inovações não se restringem apenas aos processos técnicos, mas alcançam um nível de diversificação de produtos do setor agrícola, que deixa de ser um mero suporte de produtos primários para o setor industrial e ganha cada vez mais o status de uma frente ampla de negócios rentáveis com produtos agrícolas de cultivo e usos cada vez mais flexíveis.

É notável, porém, pouco explorado, o fenômeno atual das culturas e commodities "Flex", denominadas assim, devido aos seus múltiplos usos (agroalimentares, agronergéticos, agroquimicos, dentre outros) que podem ser alterados e aplicados industriallmente de forma flexível. As culturas flexíveis incluem, mas não se limitam à soja (alimentos para animais, alimentos, biodiesel), cana-de-açúcar (alimentos, etanol), óleo de palma (alimentos, biodiesel, usos comerciais / industriais) e milho (alimentos, alimentos, etanol) (BORRAS JR., 2014).

A adoção generalizada de novas tecnologias, a integração técnica agriculturaindústria - cruciais para a elevação da produtividade - e a integração de capitais, mediante a fusão-centralização de capitais (bancários, industriais, agrários etc.) por instituições e sociedades controladoras de liquidez e financiamento (DELGADO, 2012), flexibiliza a 
estrutura produtiva e institucional em torno da organização da agricultura, permitindo ao capital agir de forma mais seletiva quanto à inserção dos espaços, cujos recursos lhe convém para a ampliação do mercado mundial.

A lógica extraterritorial de reprodução socioespacial do capitalismo, é destacada por Harvey (2005, p. 48) como um movimento de "expansão geográfica para novas regiões, incrementando o comércio exterior, exportando capital e, em geral, expandindo-se rumo à criação do que Marx denominou o mercado mundial”. Sob essa lógica, a reestruturação produtiva da agricultura tem em vista flexibilizar as barreiras sociais em torno dos territórios rurais, subsumindo o trabalho camponês ao capital, para com isso, monopolizar os seus recursos. A agricultura cientifica a serviço dos interesses do capital se apresenta aparentemente inexorável pela força demonstrada pelo agronegócio, sob a forma de dois processos: 1) a territorrialização do capital, mediante a apropriação de terras e; 2) a monopolização dos territórios pelo capital, extraindo renda da terra sem necessariamente expropriar o campesinato, através da sua subalternização empreendida pela dita integração e/ou verticalização da produção produtiva (OLIVEIRA, 2010).

Essa é a tendência mundial, haja vista a agricultura ser regida, não mais pela racionalidade camponesa, mas pela expansão da base de valorização do capital. O objetivo é intensificar a exploração econômica das fronteiras agrícolas, mediante a concentração de parcelas maiores de terra e a elevação da composição orgânica do capital (capital fixo e capital variável), tendo em vista a extração de mais-valia relativa.

A agricultura cientifica é um produto da lei de desenvolvimento da relação do valor (MARX, 2011), ou seja, ela resulta do processo global de produção capitalista, que passa a depender mais do avanço da ciência e da tecnologia, de forma que:

[...] a mesma quantidade de força de trabalho tornada disponível por um capital variável de volume de valor dado, mobiliza - elabora, consome produtivamente -, em consequência dos métodos de produção peculiares que se desenvolvem no interior da produção capitalista, uma massa sempre crescente de meios de trabalho, maquinaria e capital fixo de todo tipo, matérias-primas e materiais auxiliares, no mesmo intervalo de tempo e, por conseguinte, também um capital constante de volume de valor sempre crescente. Essa diminuição relativa crescente do capital variável em relação ao capital constante [...] é idêntica ao aumento progressivo da composição orgânica do capital social em sua média. E, do mesmo modo, não é mais que outro modo de expressar o desenvolvimento progressivo da força produtiva social do trabalho (MARX, 2017, p. 252). 
Essa elevação da composição orgânica do capital pressupõe a assimilação e decomposição das formas de economia camponesa resistentes, na medida em que a integração indústria-agricultura implica no aprofundamento da subsunção do trabalho vivo ao trabalho morto, o que no meio agrário significa o aumento do poder de barganha do agronegócio sobre o campesinato. Os métodos considerados arcaicos e irracionais da agricultura são substituídos pela aplicação direcionada para fins estritamente econômicos da tecnologia e da ciência (MARX, 2012).

É o grau dessa integração agricultura-indústria em cada país, que condiciona a intensidade e amplitude com que se realiza a expropriação do camponês, a concentração fundiária, a proletarização, a precarização das relações de trabalho no campo, a desintegração da economia natural e do modo de vida camponês (LÊNIN, 1982). Sob a égide da agricultura científica, se altera a correlação de forças no campo em favor do agronegócio, ampliando o contingente de camponeses excluídos socialmente e de trabalhadores rurais em condições precárias, haja vista se necessitar cada vez mais de terra, recursos naturais e cada vez menos de gente no campo.

A transformação capitalista do processo de produção agrícola pressupõe a expropriação camponesa da terra e dos seus meios de produção, a transformação de parte dos camponeses em agricultores capitalistas e de industriais em grandes proprietários de terra ou ainda, em países como o Brasil, o impedimento os camponeses ao acesso à terra e aos demais meios de produção (OLIVEIRA, 2010).

Isso sugere o aprofundamento da fragilidade da condição camponesa. A transformação da feição do campesinato é um processo tendencial, com o fito de subordinar a organização da unidade de produção familiar camponesa e de despojamento - não linear e nem isento de resistência - por parte dos camponeses dos seus meios de produção e reprodução individual.

É devido ao acirramento desse processo, que se aprofunda a condição subordinada do camponês brasileiro, que se formou e consolidou ao longo do século XX (OLIVEIRA, 2001), travando lutas a partir dos anos 1950, para ter acesso à terra, contra a sua subordinação e os seus efeitos deletérios sobre organização da vida no campo. Apesar da tendência à diferenciação do campesinato (KAUTSKY, 1986) e em certa medida da sua proletarização, a agricultura camponesa resiste, se contrapondo ao projeto conservador de desenvolvimento da economia centrada no agronegócio. 
O território da economia do agronegócio predomina e se amplia, mediante processos de expropriação ou subordinação do campesinato, gestados através de políticas de desenvolvimento e projetos de modernização conservadora da agropecuária, que propõem como progresso e meio para a inclusão social do camponês, a sua integração às cadeias produtivas agroindustriais (OLIVEIRA, 1994).

\section{QUESTÃo AGRÁRIA E A INTEGRAÇÃO CAMPONESA AO CAPITAL}

O capitalismo se desenvolve em meio não capitalista, eliminando progressivamente as economias naturais (LUXEMBURGO, 1985) ${ }^{1}$, consideradas como formações socioeconômicas arcaicas e atrasadas, que para a marcha do progresso devem ser suplantadas pela modernidade do capital. Em sua mundialização, a formação econômica e social capitalista combina diversos modos de produção numa unidade orgânica e funcional para o sistema mundial, que se desenvolve espacialmente de forma desigual, assimilando quando necessário para a sua reprodução, os resquícios de economias pré-capitalistas.

Esse processo de eliminação, que não se dá de forma homogênea e universal nem no tempo e no espaço, é desigual e heterogêneo. No campo, por exemplo, a expansão da relação de produção capitalista não realiza a absoluta diferenciação e destruição do camponês que, no contexto da economia agrária europeia se situou, a priori, como um sujeito social de fora do capitalismo e a posteriori como um sujeito antagonista e resistente ao avanço do modo de produção do capital (LÊNIN, 1982).

Ao contrário, no contexto brasileiro, o campesinato resulta como classe antagônica, produto da economia agroexportadora (FURTADO, 2007) implantada pelo sistema-mundo no país, desde a sua fase de expansão colonial até a primeira os anos 1950. Ele é um sujeito social integrante da formação da economia capitalista brasileira, cujo território é resultado da apropriação e destruição do território indígena, simultânea ao nascimento da luta dos escravos negros contra fazendeiros rentistas e da luta dos posseiros por terras de trabalho e contra a estrutura social, que os gera num movimento de resistências e de

\footnotetext{
${ }^{1}$ São economias pré-capitalistas. Na Europa ocidental, onde o sistema capitalista se originou se caracterizavam pelos resquícios da organização feudal, das corporações de profissionais urbanos e da produção simples de caráter estritamente camponês/artesanal. No restante do mundo, se tratavam de formações socioeconômicas tradicionais do tipo comunal ou tribal de camponeses, artesãos, caçadores coletores, com traços feudais, servis ou congêneres (LUXEMBURGO, 1985).
} 
recriação da unidade de produção familiar, das roças comunitárias e da produção coletiva, que caracteriza o território dos posseiros libertos, do camponês brasileiro (OLIVERIA, 1989).

No caso brasileiro, o capitalismo atua desenvolvendo simultaneamente, na direção da implantação do trabalho assalariado, no campo em várias culturas e diferentes áreas do país, como ocorre, por exemplo, na cultura da cana-de-açúcar, da laranja, da soja etc. Por outro lado, este mesmo capital desenvolve de forma articulada e contraditória a produção camponesa. Isto quer dizer que parto também do pressuposto de que o camponês não é um sujeito social de fora do capitalismo, mas um sujeito social de dentro dele (OLIVEIRA, 2001, p. 185).

O campesinato é entendido aqui para além da condição de categoria histórica, sujeito social ou um modo de produzir e manejar recursos naturais. Ele está vinculado a agroecossistemas locais e específicos de cada zona, sobre os quais utiliza um conhecimento diferenciado e condicionado pelo nível tecnológico de cada momento histórico e o grau de apropriação de tal tecnologia. Daí o campesinato manifestar-se e distinguir-se em graus diversos de "camponesidade", cuja definição deve estabelecer-se desde a sua consideração como um segmento composto por unidades de produção e consumo familiar que a despeito das mudanças históricas, sempre mantiveram características próprias até a sua conceituação agroecológica atual. Em síntese e de forma mais abrangente, ele consiste em uma forma particular de relação com a natureza, com a qual interage num processo de coevolução (GUZMÁN; MOLINA, 2013).

Nessa linha de raciocínio, em meio às relações capitalistas de produção no campo e cada vez mais envolvido pelo mercado, o campesinato brasileiro não se demonstra como um sujeito social passivo e inerte frente ao movimento da sua desconstituição social, a partir do processo de diferenciação-proletarização subjacente à sua integração capitalista agroindustrial. A sua (re)criação é produto da resistência e luta política contra a homogeneização produtiva e social, empreendida pelo capital na agricultura.

Nesse sentido, não há como compreender a questão agrária e a condição camponesa sem vislumbrá-las a partir da perspectiva da dinâmica de expansão territorial da agricultura capitalista. Para Haesbaert (2004, p. 20) "não há como definir o indivíduo, o grupo, a comunidade, a sociedade sem ao mesmo inseri-los num determinado contexto geográfico, 'territorial'”. 
Portanto, compreender a condição camponesa, sua economia e modo de organização social, significa confrontar dialeticamente tais relações sociais não capitalistas com as relações sociais capitalistas. Essa visão encontra fundamento, conforme os termos de Fernandes (2009, p. 201):

\begin{abstract}
O capitalismo se estabelece com a consolidação do território capitalista. Dizer que as relações sociais capitalistas produzem relações sociais não capitalistas também é dizer que os territórios capitalistas produzem territórios não capitalistas. Esta produção ocorre de modo desigual e conflitante, gerando disputas territoriais permanentes.
\end{abstract}

Em suas diferentes formas de manifestação social: posseiros, rendeiros, assentados, pequenos proprietários, o campesinato resiste e recria-se, a partir de processos socioeconômicos e socioespaciais, como: o arrendamento da terra, migração; a territorialização da luta pela terra e da agroecologia, dentre outras formas. Contrariando o prognóstico feito ao final do século XIX, por Lênin e Kautsky sobre o seu desaparecimento em meio ao desenvolvimento desigual do capitalismo. O paradigma do capitalismo agrário difunde ao final do século XX, o método de análise em que esse desaparecimento consiste do processo de metamorfose do agricultor camponês em agricultor familiar. A questão existencial imposta ao camponês sob esta lógica consiste do dilema entre escolher transformar-se em agricultor familiar, integrado ao mercado ou manter sua identidade e desintegrar-se (FERNANDES, 2002; FERNANDES, 2013). O quadro da questão agrária em que o camponês brasileiro se situa, corrobora o pensamento de Shanin (2005, p. 2) acerca da heterogeneidade dos camponeses enquanto classe social e sujeito histórico:

\footnotetext{
Os camponeses não podem ser, de fato, compreendidos ou mesmo adequadamente descritos sem sua estrutura societária mais geral; e o mesmo é válido para o contexto histórico (na realidade, apenas analiticamente é possível dividir "o diacrônico" e "o sincrônico" nos fenômenos sociais). Enfim, o termo "camponês" pode ser usado, e tem sido usado como mistificação. [...] O que está em pauta é a maneira como esse conceito opera no processo de conhecimento das sociedades.
}

Assim, como a questão agrária pode assumir formas diferenciadas de manifestação, conforme o desenvolvimento capitalista no campo em cada país, a classe camponesa poderá assumir correspondentemente caracteres tão variados e se conformará 
diante do capital tão distintamente de um lugar para o outro, que o estabelecimento de uma compreensão genérica e única se tornará problemático.

Woortmann (1990), fala do "grau de campesinidade", como uma qualidade encontrada em tempos e lugares distintos, que expressa a importância de valores da ética camponesa para indivíduos ou grupos específicos, podendo apresentar-se em maior ou menor grau, de acordo com a trajetória de vida e a forma de integração desses povos do campo à sociedade moderna capitalista.

O que o capitalismo possibilita, entretanto, formular sobre o campesinato frente ao desenvolvimento da relação do valor, é que alcançando o estágio maior dessa relação na agricultura, a partir da sua industrialização, transformam-se radicalmente os processos de trabalho no campo, modificando substancialmente o caráter da mão de obra ocupada na agricultura que, em substituição às formas antigas de relação familiar e dependência pessoal, forma-se um grande contingente de assalariados no campo ou de trabalhadores precários, miseráveis que se submetem às condições de trabalho ilegais.

Esta situação vem corroborar Oliveira (1981) quando traz a questão da intersecção de formas sociais de produção, coexistência e contradições. Existe assim uma conflitualidade constante entre agricultura de mercado e a produção do campesinato, o conflito se caracteriza na medida que há resistências ao avanço homogeneizador do modelo que tenta subalternizar o campesinato através do domínio direto da produção, quando não nesta perspectiva, através do domínio das leis que regem a produção local/regional/nacional.

A passagem da subordinação indireta (relativa autonomia da força de trabalho em relação ao capital) do trabalho ao capital no campo, para a subordinação direta (subordinação econômica propriamente dita) é uma tendência do sociometabolismo do capital no campo. Ela significa a acentuação da impossibilidade de reprodução de formas independentes baseadas na pequena produção, caracteristicamente camponesa ou de formas em que o agricultor camponês mantenha o controle do processo de trabalho (SILVA, 1996).

Nesse sentido, a ocorrência de formas tradicionais de agricultura, baseadas em relações familiares e comunitárias, dependerão das formas de resistência, muitas delas pautadas por uma negação dialética ao avanço do capital no campo, bem como das articulações estabelecidas com o poder público, no sentido de tentar permear o Estado e garantir condições concretas para a preservação do caráter camponês da agricultura.

Essa tem sido a perspectiva dos movimentos populares no campo brasileiro, sobretudo na atualidade, cujos eixos estratégicos da luta agrária não se limitam apenas ao 
acesso à terra, mas visam à apropriação dos meios técnico-científico-informacionais (SANTOS, 2000) e político-econômicos para a consolidação de uma agricultura camponesa, que social e ecologicamente pretende fazer frente ao avanço territorial da economia do agronegócio.

O debate acerca da questão agrária no início do século XXI é redimensionado pelas lutas sociais, políticas e acadêmicas travadas pelos movimentos campesinos no sentido da contraposição do paradigma da questão agrária ao do capitalismo agrário. Não se trata apenas da luta pela posse da terra ou contra uma classe de proprietários, mas contra um modelo de desenvolvimento agrícola e agrário que tem se tornado cada vez mais hegemônico, mediante a expansão territorial do poder dos CAIs sobre os recursos do campo e das florestas, alvo da estrangeirização, commoditização e financeirização da natureza.

Assim, defronta-se o campesinato com uma questão agrária cada vez mais complexa, que guarda antigos, mas incorpora novos elementos referenciados nas formas de resistência dos trabalhadores ao agronegócio, na luta pela terra e a implantação de assentamentos rurais simultaneamente à intensificação da concentração fundiária. Desdobrase, portanto, uma disputa política por diferentes projetos de desenvolvimento do campo (FERNANDES, 2000). No contexto atual da economia agrária brasileira, esboça-se um conflito entre um projeto camponês de desenvolvimento agroecológico e o projeto de desenvolvimento do agronegócio, associado à difusão (semi)periférica do novo padrão de especialização primário-exportadora (OSÓRIO, 2012), que induz países (semi)periféricos a viabilizar o território nacional, mediante a especialização regional, para atender à seletividade espacial do capital financeiro na agricultura (TOLEDO, 2007).

Os interesses de investidores externos em garantir acesso às reservas de biomassa em geral, à terra agrícola destinada à produção futura de alimentos, matérias-primas, agrocombustíveis e madeira têm induzido a transformação radical do perfil de regiões agrícolas em todo o mundo (WWF, 2012). Esse movimento é essencialmente catastrófico para os povos do campo que, situados em tais regiões, sofrem o impacto dessa globalização perversa, que desterritorializa formas outras de organização socioeconômica e socioambiental, lançando à pobreza ou à condição de trabalhadores do campo subordinados, contingentes cada vez maiores de camponeses.

Isso tem se dado na América Latina, por exemplo, como um redirecionamento da divisão internacional do trabalho para um processo de especialização produtiva em commodities e insumos industriais (minerais, siderúrgicos, alimentos, celulose, 
agrocombustíveis e energia em geral), entravando a diversificação produtiva e reforçando o papel dos países periféricos fornecedores de mercadorias de baixo valor agregado e baixa incorporação tecnológica (MANCIO; MOREIRA, 2012).

Situado na (semi)periferia do globo, o Brasil tem sido alvo desse movimento, haja vista estar dentre os países do mundo visados pelo seu potencial agrícola, seja para a produção agroalimentar, agroenergética e/ou agroextrativista. Isso tem induzido a sua economia a se submeter a esse padrão de especialização imposto globalmente pelas necessidades do capital de abrir novas frentes de acumulação, mediante a mercantilização das terras agrícolas, negociadas com investidores ávidos por oportunidades de lucro.

Esse movimento tem implicações diretas sobre o aprofundamento da questão agrária brasileira e é fundamental para se compreender a complexidade da condição camponesa em meio à intensificação da territorialização do agronegócio, através da infraestrutura fundada no latifúndio, na produção monocultora, na política de agroexportação e no controle técnico-científico-informacional, comercial e financeiro, que implicam na subordinação do agricultor camponês.

A subordinação se dá por diversas formas pelas quais o capital se aproveita dessa organização socioeconômica camponesa para se apropriar de parcelas de valor excedente, mais-valia produzida pela força de trabalho do homem e da mulher do campo. A integração da agricultura com o capital industrial e financeiro, agora mediada pelos CAIs é uma delas.

A integração consiste da organização da cadeia de produção dentro de um mesmo ramo de produção; ela se caracteriza pela internalização das decisões organizacionais por parte das empresas produtoras, que "tomam para si" o controle dos estágios produtivos a montante ou a jusante das cadeias de suprimentos. É uma estratégia de coordenação produtiva, que tem por fim possibilitar às firmas "um maior domínio sobre diferentes etapas de seu canal de distribuição e respectivo maior controle sobre ações conduzidas, viabilizando, dessa forma, uma maior eficiência na coordenação e gerenciamento da produção e/ou distribuição" (SILVA et al., 2009, p. 47).

Ela leva à subordinação não econômica, pois ela submete o camponês à uma estrutura de gestão institucional da cadeia de suprimentos, que lhe extirpa qualquer meio de empoderamento, que por sua vez lhe permita apropriação de valor e acumulação de vantagens (ROMANO, 2008), bem como à subordinação econômica, pois sob a dinâmica da integração, parte da renda da terra, valor produzido pela força de trabalho camponesa, é transferida para a cidade ou outros setores da economia, particularmente o industrial e o financeiro, 
possibilitando oportunidades de acumulação de capital, a partir da subordinação camponesa no âmbito da relação capital-trabalho (NETO, 1998).

Martins (1986) argumenta que essa parcela de valor potencialmente retida pelo camponês, acaba por fluir para os bancos, devido à dependência creditícia dos primeiros do crédito e parte também acaba por incrementar a taxa de lucro de grandes empresas industriais, que se beneficiam da produção camponesa com o barateamento da reprodução da força de trabalho industrial. No mesmo sentido, Silva et al. (2009, p. 51) entendem a integração como uma estratégia "alternativa de apropriação de valor da produção por parte da indústria de alimentos e produtos agrícolas".

A transferência intersetorial de mais-valia, decorre da subsunção da força de trabalho camponesa ao capital que, sob o estágio de desenvolvimento da agricultura cientifica, subordina a agricultura camponesa aos CAIs e à economia do agronegócio de um modo geral, impondo termos de troca desiguais. O quantum de valor que o camponês se apropriaria monetariamente, se o trabalho não fosse realizado por ele mesmo, é canalizado de forma relativa e indireta para os outros setores da economia.

Paulilo (1990, p. 19) exemplifica a condição desigual dos termos de troca da seguinte forma:

Tecnicamente este sistema é definido como uma forma de articulação vertical entre empresas agroindustriais e pequenos produtores agrícolas, em que o processo de produção é organizado industrialmente, ou o mais próximo possível deste modelo, com a aplicação maciça de tecnologia e capital. São produtores integrados aqueles que, recebendo insumos e orientação técnica de empresa agroindustrial, produzem matéria-prima exclusivamente para ela.

Não se descartando ainda, a possibilidade de que parte da renda "não- realizada" pelo agricultor camponês venha também a ser transferida para o próprio setor agrícola, mais especificamente, para os complexos agroindustriais.

Os mecanismos de interceptação que determinam a forma principal de apropriação da renda "não-realizada" do pequeno produtor, hipoteticamente, se configuram nas próprias relações entre o agricultor e os sistemas de crédito rural; nas estruturas de comercialização e nos preços dos produtos agrícolas, e também têm a ver com as alocações intersetoriais de recursos econômico-financeiros públicos e privados (NETO, 1998, p. 129-130). 
Isso desestimula a produção familiar camponesa, perpetuando a sua condição de sujeito subordinado econômica e socialmente (WILKINSON, 1986). A integração ao circuito da economia capitalista e a sua diferenciação em agricultor familiar é operada, afirmando que assim, organizações comunitárias socioeconomicamente rarefeitas estariam a ser inseridas economicamente e incluídas socialmente. Como apresentam Fernandes, Welch e Gonçalves (2014) nesse contexto existe uma diferença não só nominal, mas também ideológica. As stakeholders (partes interessadas) lutam para que uma visão paradigmática prevaleça, a do capitalismo agrário visa unificar as duas agriculturas em um mesmo contexto integrantes do agronegócio, enquanto a da questão agrária diferencia pontual e estruturalmente o papel do campesinato na agricultura brasileira. MDA e MAPA são a materialização estatal dessa divisão real dos projetos de desenvolvimento para o campo (MDA extinto em 2016-2017).

O marco desse projeto de desenvolvimento brasileiro no campo é o Programa de Aceleração do Crescimento Econômico - PAC, implementado durante o governo Lula-Dilma (2003 - 2017), que incorporou:

Uma lógica neodesenvolvimentista, ancorada na expansão do crédito para grandes empresas e na realização de grandes obras intensivas em uso dos recursos naturais. O Brasil assume mais uma vez o papel de fornecedor de matéria-prima e energia para os países do Norte e novos mercados em expansão, num processo definido por alguns como de "reprimarização" da economia" (ETTERN, 2011, p. 20).

A reprimarização é um signo da incorporação de novas áreas, até então à margem do circuito mundial da acumulação capitalista. Ela caracteriza um momento políticoeconômico, ou seja, viabilizado pelo Estado, de direcionamento de capital para a exploração de áreas, até mesmo protegidas pelo poder público, agora mercantilizáveis, tendo em vista a geração de dividendos econômicos para o capital vinculado aos setores de energia, infraestrutura, agronegócio, de produção de papel e celulose, dentre outros, o que não se realiza sem impactos socioambientais sobre os extratos mais vulneráveis da população no campo.

Observa-se um avanço, sob formas de acumulação primitiva de capital, tal e qual o que se processou durante o período colonial, no sentido da expropriação violenta das formas remanescentes da produção familiar, artesanal, camponesa e dos povos tradicionais e indígenas, dependentes em sua reprodução social da base material - dos recursos naturais de 
uso comum - apropriada pelo acionamento do motor agrodesenvolvimentista, financiado pelo Estado.

O que se ignora por parte da condução político-econômica nacional, é que a manutenção da estrutura agrária brasileira, não se constitui numa problemática apenas para as poluções subalternas do campo, mas implica na própria subalternidade e dependência da nação aos interesses de grupos transnacionais, que se aproveitam de todo o ambiente políticoinstitucional e infraestrutura provido pelo Estado, para a consolidação de seus projetos agroindustriais.

Em meio a essa dinâmica mundial, assumida pela questão agrária brasileira no século XXI, o campesinato é condicionado a reorientar sua luta contra um padrão de acumulação e desenvolvimento rural do capital, que se impõe globalmente ao espaço agrário nacional. Nas palavras de Carvalho (2005, p.3):

\footnotetext{
Esse padrão de desenvolvimento rural determinado pela dinâmica da reprodução e expansão capitalista no campo induz, também, objetiva e subjetivamente o campesinato a adotar formas de produção (tipos de produtos, de insumos, de tecnologias e a introdução de novas relações sociais de produção) que lhe são intrinsecamente prejudiciais e o impele a um impasse existencial perverso: ou adota a racionalidade capitalista, negando o modo de ser e de viver camponês - a racionalidade camponesa, ou seus membros se proletarizam.
}

O Estado tem viabilizado essa introdução de novas relações sociais de produção no campo, sob o pretexto de reparar o dano social causado aos produtores camponeses pela estrutura fundiária concentrada, mediante políticas públicas que visam o estabelecimento de relações socioprodutivas entre segmentos da sociedade completamente antagônicos, das quais se beneficiam apenas aqueles que detêm o controle dos meios de produção e controlam as instâncias gestoras das cadeias produtivas dos complexos agroindustriais.

Um problema em relação a esse aspecto político-institucional da questão agrária e a forma como campesinato vai se comportar diante dele e por ele vai ser afetado, diz respeito ao fato da questão agrária se constituir num conjunto de problemas inerentes ao capitalismo, que para serem amenizados, necessitam de políticas de caráter socioeconômico, cuja efetuação é a questão, pois somente as lutas pela terra e pela reforma agrária não são suficientes para amenizar os problemas (FERNANDES, 2000). 
Essa é a dicotomia político-institucional vivenciada pelos agricultores e trabalhadores sem-terra, que na atualidade, mesmo almejando uma revolução agrária, a partir dos seus programas de ação e projetos de desenvolvimento para o campo brasileiro, se deparam com a necessidade de se ajustar ao reformismo político, tendo em vista reduzir os efeitos deletérios da estrutura agrária segregacionista sobre a vida das populações campesinas.

Sobre o caráter reparador das políticas agrárias e agrícolas institucionalizadas pelo Estado brasileiro, longe de se constituírem em políticas sociais e participativas, voltadas à promoção da ascensão social e autonomia das classes subalternas no campo, pode-se observar segundo Flexor (2009, p. 5) que:

Os processos de institucionalização alocam recursos, privilegiam e delegam poder a certos atores em detrimento de outros, impedem a participação de determinados grupos não reconhecidos ou legitimados, promovem incentivos e cristalizam lutas políticas e interesses anteriores. Dessa forma, atores dispondo de amplas capacidades de ação podem tentar tirar proveito do processo de institucionalização mantendo seus interesses ou valores ao longo do tempo. Por exemplo, grupos bem organizados e com bons canais de comunicação com órgãos do governo podem influenciar decisões políticas ou o conteúdo de um projeto de lei, fazendo prevalecer os seus interesses nas instituições durante um amplo horizonte de tempo.

O campesinato não está fadado necessariamente ao desaparecimento, mas a lidar de maneira cada vez mais revolucionária, em cada contexto nacional, com a questão agrária, pois sua solução nos marcos do sistema capitalista é impossível, sua superação implica superar o próprio sociometabolismo do capital, requer a reinvenção de estratégias e meios, a construção de alternativas à racionalidade do agronegócio. É um sujeito com potencial de transformação da realidade agrária, na medida em que resistir à sua desconstrução social, significar lutar não apenas por uma questão de redistribuição simples de terra, mas por um projeto político de desenvolvimento para o campo, que pressuponha a transformação da sociedade geral em que ele vive, ou seja, para além da agricultura e do espaço agrário. 


\section{CONSIDERAÇÕES FINAIS}

A questão agrária é uma problemática estrutural aprofundada pelo desenvolvimento da relação do valor. Enquanto aspecto estruturante do modo de produção, não pode ser superada sem a consequente superação da lógica de desenvolvimento socioeconômico e socioespacial do capital.

Nas atividades agrícolas, ao revolucionar também os seus processos de produção e trabalho, ela reflete na subordinação econômica e não econômica do campesinato via subsunção da sua força de trabalho ao capital, a partir de um progressivo movimento em direção à sua integração agroindustrial, que não expropria e proletariza absolutamente os produtores camponeses, mas que garante ainda assim, a transferência de mais-valor realizado e não realizado desse segmento produtivo para o capital agroindustrial e financeiro.

As condições de vida no campo brasileiro e todas as problemáticas, que conjuntamente compõem sua face na atualidade, não se restringem mais também às especificidades nacionais, não dizem mais respeito apenas a aspectos políticos internos, estão estreitamente relacionadas aos condicionamentos da ordem global do capital, que se produz o espaço agrário, internacionalizando suas terras.

No Brasil, uma das formas de expressão da reprimarização da economia está na grande propriedade, integrada à indústria em complexos agroindustriais, que se impõem na (semi)periferia, mediante atuação orgânica do Estado ao capital, no sentido de dar vazão ao movimento autoexpansivo do capital e sua necessidade constante de reinvestir-se em novas linhas de atividade produtiva, em função dos diferenciais espaciais proporcionados por cada país.

No que se refere ao campesinato, o que se pode observar é como o Estado, pautado pelo paradigma do capitalismo agrário, tem se constituído num gestor da integração dos camponeses ao mercado e à estrutura agroindustrial via políticas de desenvolvimento rural, programas produtivos, comerciais e de financiamento (PRONAF, PAA, PNPB, dentre outros). Sob o pretexto de promover a inclusão social desses agricultores, essas políticas se pautam pelo princípio da sua diferenciação, induzido ao "descampesinamento" e a sua conversão em agricultores familiares plenamente envolvidos e orientados pela lógica de mercado.

Revela-se assim, uma dicotomia político-institucional, que aprisiona as famílias camponesas, que são "forçadas" a se ajustar ao reformismo político agrário ou agrícola, tendo 
em vista reduzir os efeitos deletérios da estrutura segregacionista do capital sobre a vida dos povos do campo brasileiro, que somente orientados em suas ações para uma radical transformação econômica e espacial agrária e a transformação da sociedade moderna, poderá desagrilhoá-los, aqui ou alhures, proporcionando-lhes os meios para a sua reprodução social de maneira humana e autônoma.

\section{REFERÊNCIAS}

BORRAS Jr., S. M. et al. Towards understanding the politics of flex crops and commodities: impacations for research and policy advocacy. Think Piece Series on Flex Crops \& Commodities (1). Amsterdam: Transnational Institute, 2014.

CARVAlHO, H. M. de. Campesinato e a democratização da renda e da riqueza no campo. Curitiba, mimeografado, 2005.

CHESNAIS, F. A Mundialização Financeira - Gênese, custos e riscos. São Paulo: Xamã Editora, 1996.

CLEMENTS, E. A.; FERNANDES, B. M. Estrangeirização da terra, agronegócio e campesinato no Brasil e em Moçambique. Observador Rural, 2013.

DELGADO, G. C. Do capital financeiro na agricultura à economia do agronegócio: mudanças cíclicas em meio século (1965 - 2012). Porto Alegre: Editora da UFRGS, 2012.

ELIAS, D. Reestruturação produtiva da agropecuária e novas dinâmicas territoriais: a cidade do campo. In: Encontro de Geógrafos da América Latina, 10, 2005, São Paulo. Anais... São Paulo: Universidade de São Paulo, 2005, p. 4475 - 4487.

ETTERN - Laboratório Estado, Trabalho, Território e Natureza do Instituto de Pesquisa e Planejamento Urbano e Regional. Relatório-Síntese: Projeto Avaliação de Equidade Ambiental como instrumento de democratização dos procedimentos de avaliação de impacto de projetos de desenvolvimento. Rio de Janeiro: IPPUR/UFRJ, 2011.

FERNANDES, B. M.; WELCH, C. A.; GONÇALVES, E. C. Os usos da terra no Brasil: debates sobre políticas fundiárias. São Paulo: Cultura Acadêmica, 2014.

Construindo um estilo de pensamento na questão agrária: o debate paradigmático e o conhecimento geográfico. 2013. 398 f. Tese (Livre-docência) Universidade Estadual Paulista, Faculdade de Ciências e Tecnologia. Presidente Prudente: São Paulo, 2013. 
Políticas públicas, questão agrária e desenvolvimento territorial rural no Brasil. In:

GRISA, C.; SCHNEIDER, S. (Org.). Políticas públicas de desenvolvimento rural no Brasil. Porto Alegre: Editora da UFRGS, 2015, v. 1, p. 381-400.

A questão agrária no limiar do século XXI. In: Encontro Nacional de Geografia Agrária, 15, Goiânia, 02 a 05 de dezembro de 2000 Anais..., CD-ROM.

Agricultura familiar e agricultura camponesa. In: Encontro Nacional de Geógrafos, 13, 2002, João Pessoa. Resumos... João Pessoa: Associação dos Geógrafos Brasileiros, 2002. Sobre a Tipologia de Territórios. In: SAQUET, M. A.; SPOSITO, E. S. (Org.). Territórios e territorialidades: teorias, processos e conflitos. São Paulo: Expressão Popular, 2009.

FLEXOR, G.; KATO, K. A construção institucional do mercado de biodiesel no Brasil. In: Congresso da Sociedade Brasileira de Economia, Administração e Sociologia Rural, 47,2009, Porto Alegre. Anais..., 2009.

FREDERICO, S. Expansão da fronteira agrícola e emergência de uma agricultura científica globalizada no território brasileiro. Revista Geográfica de América Central, Número Especial EGAL, 2011.

FURTADO, Celso. Formação econômica do Brasil. São Paulo: Companhia das Letras, 2007.

GUZMÁN, E. S.; MOLINA, M. G. Sobre a evolução do conceito de campesinato. 2. ed. São Paulo: Expressão Popular, 2013.

HAESBAERT, R. O mito da desterritorialização: do "fim dos territórios" à multiterritorialidade. Rio de Janeiro: Bertrand Brasil, 2004.

HARVEY, D. A produção capitalista do espaço. 2. ed. São Paulo: Annblume, 2005.

KAUTSKY, K. A questão agrária. Tradução de Otto E.W. Maas. Rio de Janeiro: Laemmert, 1986.

KHALILI, A. Commodities ambientais em missão de paz: novo modelo econômico para a América Latina e o Caribe. São Paulo: Nova Consciência, 2009.

KOSIK, K. Dialética do concreto. 7. ed. Rio de Janeiro: Paz e Terra, 2002.

LÊNIN, V. I. Desenvolvimento do Capitalismo na Rússia. São Paulo: Abril Cultural, 1982. LUXEMBURGO, Rosa. A acumulação de capital: contribuição ao estudo econômico do imperialismo. 2.ed. São Paulo: Nova Cultural, 1985. 
MANCIO, D.; MOREIRA, R. C. A dependência latino-americana e a reprimarização da economia. In: Encontro Nacional de Economia Política, 17, Anais... 2012, Rio de Janeiro, 2012.

MARQUES, M. I. M. A atualidade do uso do conceito de camponês. Revista NERA, Presidente Prudente, Ano 11, n. 12, p. 57-67, 2008.

MARX, K. O Capital: crítica da economia política - Livro VI - Volume VI. Rio de Janeiro: Ed. Civilização Brasileira, 2012.

O Capital: crítica da economia política - Livro III: o processo global da produção capitalista. São Paulo: Boitempo, 2017.

O Capital: Livro I, Capítulo VI (inédito). Livraria Editora Ciências Humanas LTDA, São Paulo, 1978.

. Grundrisse: manuscritos econômicos de 1857-1858: esboços da crítica da economia política. . São Paulo: Boitempo, 2011.

Formações econômicas pré-capitalistas. 5. ed. Rio de Janeiro: Paz e Terra, 1986.

MARTINS, J. S. A reforma agrária e os limites da democracia na "Nova República". São Paulo: Hucitec, 1986.

MOREIRA, R. Bioenergia, sentido e significado. Revista da ANPEGE, v. 3, p. 43 - 56, 2007.

NETO, C. C. Agricultura familiar e renda da terra. Estudos Sociedade e Agricultura (UFRJ), Rio de Janeiro, v. 10, p. 118-134, 1998.

OLIVEIRA, A. U. de. A geografia das lutas no campo. 6. ed. São Paulo: Contexto, 1994.

A longa marcha do campesinato brasileiro: movimentos sociais, conflitos e Reforma Agrária. Estudos Avançados, São Paulo, v. 15, n. 43, Dec. 2001.

. A agricultura camponesa no Brasil. 3.ed. São Paulo: Contexto, 1997.

. A questão da aquisição de terras por estrangeiros no Brasil. Agrária, são Paulo, n. $12,2010$.

. Geografia das Lutas no Campo. São Paulo: Contexto, 1989.

OLIVEIRA, A. A.; MOREIRA, C. A. L.; MARQUES, M. S. Crise Estrutural do Sistema do Capital, Dominação Sem Sujeito e Financeirização da Economia. In: Colóquio Internacional Marx e Engels, 5, Anais... 2007, Campinas: Unicamp, 2007. p. 1-10.

OLIVEIRA, Francisco de. Elegia para uma re(li)gião: Sudene, Nordeste Planejamento e Conflitos de Classes. Rio de Janeiro: Paz e Terra, 1981.

OSÓRIO, J. América Latina: o novo padrão exportador de especialização produtiva - 
estudo de cinco economias da região. In: FERREIRA, C.; OSORIO, J.; LUCE, M. (Org.). Padrão de reprodução do capital: contribuições da teoria marxista da dependência. São Paulo: Boitempo, 2012.

PAUlilO, M. I. Produtor e agroindústria: consensos e dissensos. O caso de Santa Catarina. Florianópolis: Coedição Secretaria de Estado da Cultura e do Esporte e Editora UFSC, 1990.

ROMANO, J. O. 'Empoderamento' e poder no enfrentamento da pobreza. In: COSTA, L. F. C.; FLEXOR, G.; SANTOS, R. (Organizadores.). Mundo Rural brasileiro: ensaios interdisciplinares. Rio de Janeiro: Seropédica, 2008, p. 239-253.

SANTOS, M. Por uma outra globalização: do pensamento único à consciência universal. 2 ed. Rio de Janeiro: Record, 2000.

Espaço e sociedade (ensaios). Petrópolis: VOZES, 1979.

. Sociedade e espaço: a formação social como teoria e como método. Boletim Paulista de Geografia, São Paulo, n. 54, jun., 1977.

SILVA, V. L. S. et al. Integração vertical como estratégia de apropriação de valor: um estudo exploratório no canal de distribuição de produtos agrícolas. Revista Gestão e Produção, São Carlos, v. 16, n. 1, p. 44-53, jan. - mar. 2009.

SHANIN, T.A definição de camponês: Conceituações e desconceituações - o velho e o novo em uma discussão marxista. Revista Nera, ano 8, n. 7, Jul. - Dez., 2005.

SILVA, J. G. da. A nova dinâmica da agricultura brasileira. Campinas, SP: UNICAMP, IE, 1996.

WALLERSTEIN, I. The modern world-system. Academic Press, New York, vol. III, 1989. WILKINSON, J. O Estado, a agroindústria e a pequena produção. São Paulo-Salvador: Hucitec/Cepa, 1986.

WOORTMANN, K. Com parentes não se negoceia: o campesinato como ordem moral. Anuário antropológico /87. Brasília: Editora da Universidade de Brasília, 1990.

WWF/ZSL. Relatório Planeta Vivo 2012: a caminho da Rio+20. Disponível em: <http://wwf.org.br>. Acesso em: 20 jun. 2013.

TOLEDO, M. Especialização regional produtiva e a viabilização do território nacional para o escoamento da soja. Mercator - Revista de Geografia da UFC, ano 06, n. 12, 2007. 